\title{
DO VAZIO DE PENSAMENTO À DEMOCRACIA ESPETACULAR: ANÁLISE DO IMPACTO POLÍTICO DAS FAKE NEWS NAS ELEIÇÕES PRESIDENCIAIS DE 2018
}

João Adail Camargo Luiz'

Resumo: O objetivo deste trabalho é a analisar a utilização e impacto das fake news nos últimos anos da vida política brasileira enquanto propulsão ao esvaziamento do pensamento e uma zona de anomia entre democracia e totalitarismo que captura e sacraliza a vida biológica humana ao mesmo tempo que a abandona, reconhecida como estado de exceção permanente. Para tanto, abordamos as obras de Hannah Arendt e Giorgio Agamben, bem como analisamos fenomenologicamente algumas das fake news mais divulgadas entre a população brasileira no período das eleições presidenciais de 2018. Por fim, entendemos que a verdade factual, resguardada pelas humanidades e transmitida pela mídia é capaz de levar a população novamente à percepção da realidade e ao resgate do sentido da política pela ação.

Palavras-chave: Estado de exceção; Fake News; Liberdade.

Abstract: The objective of this work is to analyze the use and impact of fake news in the last years of Brazilian political life as a propulsion for the emptying of thought and a zone of anomie between democracy and totalitarianism that captures and sacralizes human biological life while abandoning it, recognized as a permanent state of exception. Therefore, we approach the works of Hannah Arendt and Giorgio Agamben, as well as phenomenologically analyze some of the most popular fake news among the Brazilian population in the period of the 2018 presidential elections. Finally, we understand that the factual truth, protected by the humanities and transmitted by the media, is able to lead the population back to the perception of reality and to the recovery of the sense of politics through action.

Keywords: State of exception; Fake news; Freedom.

\footnotetext{
${ }^{1}$ Graduado em Filosofia (bacharelado) pela Pontifícia Universidade Católica de Campinas (PUC-Campinas). Noviço da Congregação dos Sagrados Estigmas de Nosso Senhor Jesus Cristo (Estigmatinos). Currículo Lattes: http://lattes.cnpq.br/9913707852011526.
} 


\section{Introdução}

"Uma mentira só precisa ser repetida com bastante frequência. Então ela é verossímil", proclama a famigerada frase de Joseph Goebbels, ministro da propaganda do governo nazista. Nos últimos anos, é possível notar o crescimento do acesso à informação e do uso das redes sociais para compartilhamento de conteúdo e, com isso, se abriu um espaço de fácil disseminação de notícias falsas, tiradas de contexto ou alteradas de forma tendenciosa: as chamadas fake news. Nosso texto visa discutir o manejo, impacto e contribuição de algumas notícias falsas para o aparelhamento da vida política do Brasil e da revelação de um Estado burocrático posicionado em uma espécie de "anomia" entre democracia e totalitarismo: o fenômeno do estado de exceção permanente, que hoje se dá sobre um modelo de sociedade de massas e espetáculo. Além disso, procuramos apontar, à luz do pensamento de Hannah Arendt e Giorgio Agamben, como recuperar o sentido e lugar da política ao resguardar a verdade factual, bem como o papel das humanidades e da mídia na transmissão dessa verdade a fim de que possa haver novamente um contato com a realidade, permitindo a faculdade do pensar e do agir em conjunto, o "milagre" de começar algo novo, tornando a máquina burocrática inoperosa.

Para tanto, trabalhamos com a leitura e síntese do pensamento arendtiano acerca da relação entre verdade e política, bem como os resquícios de movimentos totalitários presentes nas democracias contemporâneas, especialmente a partir da Crises da República (2018b) e Verdade e Política, ensaio publicado em Entre o Passado e o Futuro (2016b). Também abordaremos a crítica de Guy Debord e Giorgio Agamben sobre a sociedade do espetáculo. Através de uma abordagem fenomenológica, analisamos algumas das mais recorrentes fake news disseminadas pela população brasileira durante as eleições presidenciais de 2018 como exemplo de dispositivo aclamatório e sacralizador, que corrobora um modelo burocrático de governo a partir de Arendt e Agambem. Por fim, a terceira parte irá apontar o pensamento e a ação pautados na verdade factual como possibilidade de "salvação" da máquina que captura e abandona a vida humana.

\section{As ligações perigosas entre verdade, política e filosofia}

Em $O$ que é Política? (2020), Arendt enfatiza que o desencanto dos cidadãos com a vida política na atualidade é consequência da trágica experiência dos Estados totalitários, onde "toda a vida dos homens foi politizada por completo" (p. 38), e do desenvolvimento monstruoso de aparatos de destruição capazes de eliminar não só a vida humana, mas toda a 
vida orgânica da Terra. Possivelmente, ambos os casos seriam a plenificação de dois pensamentos que marcaram a tradição, a saber: a afirmação aristotélica de que o homem é zoom politikon, "como se no homem houvesse algo político que pertencesse à sua essência", e em segundo lugar a visão de que Deus criou $o$ homem à imagem da solidão de Deus, gerando o estado natural de não-sentido e a rebelião de uns contra os outros, algo que Hobbes enxergou como o início da política (ARENDT, 2020, p. 23).

Isso levou o mundo do século XX - e talvez até hoje - a preconceitos baseados na crença de que o Estado seria a sede da política e, portanto, se deveria resistir a ela para resguardar liberdades não políticas, como o pensamento e até mesmo a própria vida privada; consequentemente, a liberdade estaria dissociada da política. Além disso, a única função da política seria a sua instrumentalidade, por meio da qual se tornaria uma arma de destruição da vida terrena (JARDIM, 2011, p. 69-70).

Outro fator interessante levantado por Arendt (2016b) é a dissociação entre a filosofia e a política causada pelo pensamento de Platão, uma vez que iniciou a tradição fílosófica "com o abandono da Política por parte do filósofo", pois o mundo comum seria ilusão e treva, mundo da dóxa, e para desvelar as verdades do mundo inteligível deveria retirar-se dele; assim, poderia retornar "para impor seus padrões aos assuntos humanos" (p. 44). Se a filosofia é a busca da verdade através do uso da razão, e se por política se entende a disputa retórica na ágora que se preocupa mais com a capacidade de persuasão que com a validade dos argumentos, logicamente verdade, filosofia e política estariam distanciadas. Marx teria sido o responsável por desfazer essa separação quando declarou que "a filosofia e sua verdade estão localizadas, não fora dos assuntos dos homens e de seu mundo comum, mas precisamente neles" (ARENDT, 2016b, p. 43).

Seguindo essa perspectiva, a autora propõe que a verdade - quando tomada sob o ponto de vista político - carrega em si um caráter despótico, pois nunca poderá ser alterada quer em seu caráter racional (se trata de ciências naturais ou do próprio pensamento filosófico, desvelada através do uso da razão), ou factual (algo que ocorreu na história, no passado, totalmente irreversível); reproduzindo a frase de Grotius, aponta que "mesmo Deus não pode fazer com que duas vezes dois não seja quatro" (ARENDT, 2016b, p. 298). Entretanto,

Fatos e eventos são entidades infinitamente mais frágeis que axiomas, descobertas e teorias - ainda que os mais desvairadamente especulativos produzidos pelo cérebro humano; ocorrem no campo das ocupações dos homens, em sempiterna mudança, em cujo fluxo não há nada mais 
permanente do que a permanência, reconhecidamente relativa, da estrutura da mente humana (ARENDT, 2016b, 287-8).

Consequentemente, a verdade factual está sempre sujeita a testemunhas e existe apenas se alguém fala sobre ela, e "é política por natureza", à medida que "fatos e opiniões, embora possam ser mantidos separados, não são antagônicos um ao outro" pois "fatos informam opiniões, e as opiniões, inspiradas por diferentes interesses e paixões", podem tanto ser fiéis à verdade como deliberadamente alterá-la para se encaixar nos interesses de uma pessoa ou grupo (ARENDT, 2016b, p. 295). Nesse caso, aquele que mente torna a sua versão da verdade crível àquele público que o ouve na praça pública, e isso marcou profundamente o século XX com a confiança cega dos dirigentes do poder totalitário no poder da mentira, ao ponto de "reescreverem a história uma e outra vez para adaptar o passado à 'linha política' do momento presente, ou de eliminarem dados que não se ajustem às suas ideologias" (ARENDT, 2017, p. 17).

Embora a mentira seja um meio importante e severamente utilizado ao longo da história política, aquele que se utiliza dela sempre corre o risco de ser desmentido pela realidade, pois a mentira nunca será suficientemente grande para cobrir o fato em sua completude; portanto, a verdade sempre prevalece sobre a mentira ainda que não se mostre publicamente, afinal de contas para poder produzir uma boa mentira, é necessário que o mentiroso tenha o conhecimento da verdade (ARENDT, 2017, p. 35). Em nosso tempo, com o avanço da mídia de massa e a constante sede por informação e entretenimento, fica ainda mais fácil difundir sobre a massa um discurso ou imagem de um grupo para outro, como foi o caso dos documentos do Pentágono ${ }^{2}$ analisados por Arendt no artigo A Mentira na Política, publicado na obra Crises da República (2017), onde a preocupação dos Estados Unidos não seria de afugentar inimigos (tanto é que não há ali segredos militares possivelmente interceptáveis em espionagem), "mas estava destinada principalmente, senão exclusivamente, ao consumo doméstico, à propaganda caseira, e especialmente enganar o Congresso" (ARENDT, 2017, p. 22).

Essa produção de imagem está pautada também numa mentalidade de relações públicas, que "tem sua origem na sociedade de consumo, com seu excessivo apetite por mercadorias a serem distribuídas através de uma economia de mercado" (ARENDT, 2017, p. 17). Outro fator interessante é o surgimento dos "resolvedores de problemas", que procuram

\footnotetext{
${ }^{2}$ É uma série de registros militares que documentam o papel dos Estados Unidos na Indochina desde a Segunda Guerra Mundial até maio de 1968, intitulado como História do processo norte-americano para tomada de decisões em política vietnamita, mas publicado pelo New York Times no ano de 1971 como Os Documentos do Pentágono, título que se popularizou (Cf. ARENDT, 2017, p. 13).
} 
superar a contingência do desenrolar dos fatos a partir de uma razão enciclopédica e objetiva, diferindo do mentiroso comum porque não só guarda a verdade escondida, como também busca destruí-la e se livrar dela. Apesar da vantagem de a verdade factual poder ser adequada à plateia ou até mesmo "estraçalhada pela mentira organizada de grupos, classes ou nações, ser negada e distorcida, muitas vezes encoberta cuidadosamente por camadas de falsidade" e até mesmo ser "simplesmente deixada cair no esquecimento", há um momento em que a mentira se torna contraproducente, forçando a capacidade dos cidadãos de discernir o verdadeiro do falso (ARENDT, 2017, pp. 16-17)

Enquanto a verdade factual é única, inflexível e irreversível, a mentira tem possibilidades ilimitadas e, por isso, é capaz de retirar o chão sob os pés dos interlocutores, lançando um clima de superfluidade - isto é, de não pertença e estranheza ao mundo - e desespero. É justamente essa característica da mentira que a aproxima da política, o campo por excelência da ação humana imprevisível. Arendt (2016b, p. 319) pontua que a inflexibilidade dos fatos faz deles maiores que o poder, esse jamais pode produzir um substituto para a realidade factual, a não ser que se use de um discurso que venha a explicar toda a realidade à luz de uma ideia única (ideologia), repetida com a propaganda até a sua assimilação e - no caso dos sistemas totalitários - corroborada pelo cinturão do terror, conforme apontado em Origens do Totalitarismo (2012). O acontece a partir daqui é

Uma absoluta recusa a acreditar na verdade de qualquer coisa, por mais bem estabelecida que ela possa ser. Em outras palavras, o resultado de uma substituição coerente e total da verdade dos fatos por mentiras não é passarem estas a serem aceitas como verdade, e a verdade ser difamada como mentira, porém um processo de destruição do sentido mediante o qual nos orientamos no mundo real - incluindo-se entre os meios mentais para esse fim a categoria de oposição entre verdade e falsidade (ARENDT, 2016b, p. 317).

Uma afirmação semelhante se encontra na crítica de Debord (2005) à denominada sociedade do espetáculo, segundo a qual toda a vida social "se anuncia como uma imensa acumulação de espetáculos" onde há a valorização da imagem em detrimento da coisa, e "a realidade considerada parcialmente desdobra-se na sua própria unidade geral enquanto pseudomundo à parte, [...] onde o mentiroso mentiu a si próprio" (DEBORD, 2005, p. 8). As relações socias passam a ser mediadas por imagens projetas principalmente por meios eletrônicos; a realidade, assim, "surge no espetáculo, e o espetáculo é real. Essa existência recíproca é a essência e o sustento da sociedade existente" (DEBORD, 2005, p. 10). 
Anos mais tarde, Agamben (2015) irá descrever um exemplo real da ação do espetáculo na vida social e a maneira em que, nele, a verdade se torna apenas um "movimento necessário do falso" ao trazer o exemplo de Timisoara, uma cidade romena que sediou uma insurreição que gerou a morte de mais de 2000 pessoas:

O que o mundo inteiro via ao vivo [corpos recém-chegados a um necrotério sendo torturados pelo que seriam membros de uma facção policial adversária], como a verdade verdadeira nas telas de televisão, era a absoluta não-verdade; e, embora a falsificação fosse às vezes evidente, ela era, no entanto, autenticada como verdadeira pelo sistema mundial das mídias, para que ficasse claro que a verdade já não era mais senão um momento no movimento necessário do falso. Assim, verdade e falsidade tornavam-se indiscerníveis, e o espetáculo legitimava-se unicamente através do espetáculo (AGAMBEN, 2015, p. 57).

Na sociedade de massas, cujos indivíduos estão privados de seu lugar no mundo e por isso são obcecados "pelo desejo de fugirem da realidade" (ARENDT, 2012, p. 486), até mesmo a morte, que já é antipolítica por excelência, uma vez que nos lembra que "vamos desaparecer do mundo das aparências e vamos deixar a companhia dos companheiros humanos" (ARENDT, 2017, p. 140) se torna algo banal, pois torna-se o atestado do anonimato perante a massa "selando o fato de que ele [o indivíduo] jamais havia existido" (ARENDT, 2012, p. 600) - algo próximo da experiência dos campos de concentração.

Tendo levantado essas ligações entre verdade, política e filosofia, a retirada da realidade factual causada pela mentira organizada e sua repetição na mídia de massa e levando em conta a utilidade de tal meio no campo da política, especialmente na sociedade de massas marcada pelo espetáculo, passaremos agora a analisar uma série de discursos propagados nos últimos anos entre os brasileiros e como isso contribui para a exacerbação de um estado de guerra civil permanente que mina o processo democrático, isto é, que revela a fratura paradoxal de uma democracia autoritária do espetáculo.

\section{Burocracia e mentiras organizadas}

Com a facilidade do acesso e do compartilhamento de informações através de redes sociais, como o Twitter, Facebook e, principalmente, o Whatsapp, as últimas eleições presidenciais no Brasil foram marcadas pela massiva propagação de fake news entre a população. Recuero e Gruzd (2019, p. 32) apontam que a fake new "não se trata apenas de uma informação pela metade ou mal apurada, mas de uma informação falsa intencionalmente divulgada, para atingir interesses de indivíduos ou grupos”, distorcendo fatos e os tirando fora 
do contexto para exaltar a imagem do candidato apoiado e/ou destruir a imagem dos opositores.

É importante ressaltar o peso que as fake news carregam para os princípios morais da massa, e à luz do que foi discutido no primeiro capítulo podemos dizer que seria o suprassumo da mentira organizada, com a pretensão de se equipararem à verdade factual e organizadas sempre de modo a convencer a plateia que irá recebe-la, requerendo a "criação de outra realidade, por assim dizer, na qual elas se encaixem sem remendos, falhas ou rachaduras" (ARENDT, 2016b, p. 313). Essa pretensão de verdade é fundamental, uma vez que "cria narrativas que ecoam preconceitos e visões de mundo dos atores sociais" e, portanto, "a circulação das fake news poderia afetar também as crenças políticas, constituindo uma esfera pública parcial, partidária e universalizante para aqueles que dela participam" (RECUERO; GRUZD, 2019, p. 33). De fato, esse fenômeno foi crucial para o resultado das eleições, não cessou com a posse de Jair Bolsonaro (sem partido).

Foi marcante na ascensão de Bolsonaro a produção de inimigos, que recai especialmente na figura dos opositores eleitorais. Segundo Maranhão Filho et. al. (2018), “a lógica que norteia a produção do inimigo é aquela que busca estabelecer sacrifícios necessários em nome de um "bem maior", seja este a nação, a 'família', a ordem [...]" e, no caso do Brasil, instituições religiosas. Uma vez que a democracia de massa "procura prever a reação da massa antecipando-se a seus gostos", como um produto a ser consumido pelo povo, o potencial inimigo sofre com estratégias de imagem e linguagem que visavam "direcionar a 'opinião pública' da massa e seu comportamento" (RUIZ, 2017).

É o caso de Manuela d’Ávila $(\mathrm{PCdoB})$ e Fernando Haddad $(\mathrm{PT})$, candidatos à presidência na chapa que disputou o segundo turno das eleições com Bolsonaro. Circulou pelas redes sociais uma imagem onde a então candidata abre um casaco para expor uma camiseta com a estampa de um arco-íris acompanhada da frase "Jesus é travesti"; a imagem foi desmentida pela própria candidata em seu perfil do Twitter, onde publica a imagem original em que a camiseta leva a palavra "rebele-se" (VELASCO, 2018).

$\mathrm{Na}$ época, o Tribunal Superior Eleitoral ainda exigiu que o Facebook retirasse do ar 33 fake news relacionadas à Manuela e identificasse os seus autores. Em reportagem do Estadão, Luiz Vassallo et. al. (2018) afirmam que os advogados da chapa levantaram conteúdos que incluíam vídeos onde, supostamente, a candidata estaria em uma manifestação no Rio de Janeiro, "na qual há imagem de dois manifestantes distribuindo imagens de santas e chutando crucifixos", bem como um vídeo de Manuela produzido para incentivar o combate à 
homofobia nas escolas, que teve seu conteúdo deturpado com sobreposição de imagens. O ministro Sérgio Banhos (TSE) entendeu que as publicações teriam a finalidade de "manchar a imagem da candidata perante o público católico e cristão, com o objetivo evidente de interferir no pleito eleitoral", além do fato que

A mídia foi claramente editada com uso de montagem - por meio da qual se desvirtuou o conteúdo original do vídeo produzido pela candidata representante para combater a homofobia nas escolas -, contendo agressão e ataque à imagem da candidata, atribuindo-lhe conceito sabidamente inverídico (VASSALLO, 2018).

Outro fato a ser considerado é a entrevista do então candidato Bolsonaro (sem partido) para o Jornal Nacional, da Rede Globo de Televisão, que mostrou às câmeras o livro Aparelho Sexual e Cia afirmando que seria parte do projeto "Escola sem Homofobia" discutido quando Haddad esteve à frente do Ministério da Educação, cujo fim seria auxiliar professores no combate à violência e preconceito nas escolas públicas, pejorativamente intitulado pelos opositores como "kit gay" (DELLA COLETTA, 2018). No entanto, "o livro em questão nunca fez parte do projeto Escola sem Homofobia. E mais: sequer foi adquirido ou fez parte de algum programa do Ministério de Educação" (DELLA COLETTA, 2018); há apenas uma compra de 28 exemplares por parte do Ministério da Cultura para o Programa Livro Aberto, e nenhum direcionado a crianças.

Semelhante estratégia foi empregada na propagação de um vídeo que mostraria fraudes nas urnas eletrônicas usadas nas eleições brasileiras: ao digitar o número um, automaticamente o dispositivo preencheria o voto em Fernando Haddad (PT). Em reportagem para a revista Veja, Lellis (2018) dissecou o vídeo e encontrou várias distorções no layout da urna que revelam uma manipulação de imagem, além de apontar que o compartilhamento dessa informação foi impulsionado pelo então candidato a senador Flávio Bolsonaro (PSLRJ), filho do presidente Bolsonaro em sua conta do Twitter, que apagou a publicação logo que o TSE lançou nota a respeito. Uma publicação de Ramos (2018) para a Piauí ainda aponta mais de trinta verificações de informações relacionadas a fraudes nas urnas, como o boato que a Polícia Federal teria apreendido uma van contendo urnas adulteradas, a maioria preenchida com pelo menos $72 \%$ dos votos para Fernando Haddad (PT). Dado importante é que Bolsonaro questionou a segurança das urnas variadas vezes e sempre defendeu o voto impresso (RAMOS, 2018).

Esses são alguns exemplos de como "as atuais democracias fizeram da política uma encenação por meio da qual reduzem os cidadãos a meros espectadores passivos" que 
assistem ao movimento eleitoral "com a ilusão de participarem na medida que podem opinar com reações espontâneas próprias de um espectador ante um espetáculo" (RUIZ, 2017).

Podemos afirmar que isso é resultado do processo de burocratização da sociedade em decorrência dos avanços científicos, no qual "pessoas são 'casos', sejam casos de assistência social ou casos médicos, ou, qualquer que seja o quadro de referência, casos que podem ser colocados em uma placa de computador sem as características individuais que designam a diferença entre uma 'pessoa' e um 'caso'” (FROMM, 1968, p. 99. Tradução nossa ${ }^{3}$ ). As massas de indivíduos supérfluos, isto é, isolados de suas raízes políticas e sua capacidade de agir, e cujas relações sociais se pautam nas telas de computadores ou telefones celulares, se vêem numa espécie de "tirania sem tirano", onde todos são igualmente impotentes. Segundo Arendt (2017, p. 151),

Quanto maior for a burocratização da vida pública, maior é o atrativo da violência. Numa burocracia completamente desenvolvida, não há ninguém com quem se possa argumentar, para quem se possa apresentar queixas, ou sobre quem possa ser exercida as pressões do poder [...]. A transformação do governo em administração, ou das repúblicas em burocracias, e a desastrosa diminuição da esfera de influência pública que a acompanhou, têm uma história longa e complicada por toda a Idade Contemporânea; e este processo se acelerou consideravelmente nos últimos cem anos com o aparecimento das burocracias partidárias.

A burocracia no sistema democrático é como um fermento - um "bacilo" totalitário que, ao levedar, enche as massas de violência e as leva a agir para transformar o mundo não adequado à ideologia que naquele momento os imuniza da realidade; apesar de ter sido considerada única alternativa política no mundo pós-totalitário, o sistema burocrático guarda em si elementos apontados por Maia e Reinaldo (2019, pp. 68-9) como assustadoras semelhanças com as tiranias que marcaram o início do século XX, como por exemplo "o encolhimento de espaços de ação através da representação ínfima da ação por meio do voto, a burocracia da administração moderna, o tirânico governo de ninguém, a indiferença política inerente ao engodo de reduzir a participação política às cabines de votação".

Arendt (2017, p. 79) faz uma denúncia que, baseando no que discorremos até agora, se mostra muito atual, especialmente na realidade brasileira: a crise governamental da democracia se dá “em parte porque perdeu [...] todas as praxes que permitiam a real participação dos cidadãos, e em parte porque atualmente sofre gravemente da mesma doença

\footnotetext{
${ }^{3}$ No original, se lê: "persons are 'cases', ehether welfare cases or medical cases, or, whatever the frame of reference is, cases wich can all be put down on a computer card without those individual features wich designate the difference between a 'person' and a 'case"”.
} 
que o sistema de partidos", num fetichismo da burocracia e na tendência partidária "em não representar ninguém exceto as máquinas dos partidos".

As raízes desse fenômeno se fundam em três eventos que levaram os homens a se alienarem do mundo, a saber: a descoberta da América, a Reforma e o descobrimento do telescópio, que lançaram os homens contra si mesmos e os deixaram "à mingua em uma situação em que [...] ficaram expostos, de mãos vazias, às conjunturas da vida, tendo apenas sua força de trabalho para vender" (JARDIM, 2014, p. 35). Outro fator foi a desvalorização da vita contemplativa ${ }^{4}$ e valorização da vita activa, especialmente o trabalho, o que consequentemente levou a uma exaltação e desnudação da vida biológica e suas necessidades básicas (zoé) (ARENT, 2016a, p. 389).

Segundo Souki (2005), isolado em si mesmo e em posse apenas de sua vida, os homens perdem o sentido do real, o senso comum que permite a experiência do pensamento. Ocorre, portanto, um esvaziamento do pensamento, uma vez que pertencendo ao campo da contemplação não produz resultados imediatos, algo crucial para as massas; "disso resulta que a ausência de pensamento, ao proteger os indivíduos contra os perigos da investigação, ensina-os a aderir rapidamente a tudo o que as regras de conduta possam prescrever em determinada época para uma determinada sociedade" (p. 141).

O vazio - forjado artificialmente - é recoberto com a ideologia e capturado pela estrutura burocrática para criar um estado de "guerra civil permanente", uma "zona de indeterminação entre a democracia e o absolutismo", denominado por Agamben (2004, p. 13) como estado de exceção que, segundo Almeida (2020, p. 82), se constitui numa "zona de indistinção entre externo e interno, exclusão e inclusão", na qual "a ex-ceptio é o paradoxo que define o poder soberano, cujo paradigma oculto que o orienta: '[...] é o ponto de indiferença entre violência e direito [...]"’. Segundo Silva (2020, p. 73),

Arendt pensava a guerra civil mundial - o totalitarismo - em termos de uma forma muito particular de governo, em que os aparelhos de Estado, tanto em seu caráter ideológico quanto repressivo são instrumentalizados a fim de moldar toda uma sociedade dentro de uma sistema monopartidário, tendo como artífice um líder carismático que faz de sua vontade a da população, alinhado a isso com uma feroz propaganda política e social destinada a transformar o subjetivismo de cada indivíduo em benefício do Estado.

\footnotetext{
${ }^{4}$ No prefácio de A Condição Humana (2016a), Adriano Correia pontua que "Arendt recorre ao termo vita activa [...] para caracterizar o âmbito das atividades humanas fundamentais” (p. 27), que suprem a condição da vida biológica e suas necessidades (trabalho), da mundanidade (obra) e da pluralidade (ação e discurso); já a vita contemplativa é trabalhada com mais profundidade em A Vida do Espírito (2018b) e corresponde às atividades espirituais que levam o homem à ação, a saber: a faculdade de pensar, de querer e de julgar.
} 
Nesta esteira, Agamben (2015, p. 61) aponta que o Estado burocrático e espetacular que ascende nos últimos anos, apesar de sua imagem democrática, corre o risco de "ser, na realidade, a pior tirania que jamais se viu na história da humanidade, em relação à qual resistência e dissenso serão, de fato, sempre mais difíceis", um Estado que se funda na dissolução e esvaziamento de toda identidade e expressão de singularidade. A aparência é tomada pela imagem, e "as diferentes identidades que marcaram a tragicomédia da história universal estão expostas e recolhidas numa vacuidade fantasmagórica” (AGAMBEN, 2015, p. 61).

A crítica agambeniana da burocracia remonta aos debates desenvolvidos pelo cristianismo na construção de sua doutrina, principalmente no que concerne ao dogma da Trindade: um Deus que é ao mesmo tempo uno e trino, que governa o mundo ao mesmo tempo em que respeita a liberdade humana, a chamada oikonomia trinitária: "Por meio da oikonomia, Deus governa o mundo não de forma absolutista, como um soberano déspota ou um rei, mas respeitando a liberdade humana através da noção de providência" (RUIZ, 2017).

Uma hierarquia dos anjos que governam o mundo de forma ordenada (burocrática) serve de exemplo e antecipação ao governo dos homens (PFISTER, 2019, p. 102); a liturgia, opus dei, é o ritual onde um de seus elementos (dispositivos) é aclamar a Deus como soberano e senhor da história e da criação. A influência e uso político desses elementos levou à construção dos Estados modernos, e os dispositivos - dentre eles a aclamação e a sacralização - operam na captura e manutenção do Estado de Exceção.

As democracias de massa, como pudemos notar acima, utilizam da aclamação feita pela "opinião pública" em lugar do poder deliberativo, como as constantes pesquisas de aprovação do governante ou sua exaltação (RUIZ, 2017). Isso foi comum nos governos totalitários, que produziam grandes espetáculos e discursos muito bem elaborados, por isso, "Na medida em que nossas democracias tendem a legitimar efetivamente o poder através de dispositivos aclamatórios, afastando o poder deliberativo real do povo" (RUIZ, 2017), cada vez mais caímos no paradoxo da democracia autoritária.

Nesse sentido, as fake News tem um serviço duplo: tanto servem para destruir a imagem dos opositores, quanto para exaltar o governante com obras e falas que não são suas, ou com informações sensacionalistas e retiradas de seu contexto; tanto aclamam o soberano, como amaldiçoam a vida do "inimigo".

\section{Dispositivos e a possibilidade de libertação pela ação e pensamento}


Arendt (2016a) aponta que a vida se tornou bem supremo na era moderna a partir de uma inversão fundamental feita pelo cristianismo e que sobreviveu à secularização: a vida humana individual passou a tomar o lugar de imortalidade antes reservado ao mundo. Em suas palavras, "foi precisamente a vida individual que passou então a ocupar a posição antes ocupada pela 'vida' do corpo político", e

Tal como o corpo político possui uma imortalidade apenas potencial que pode ser confiscada em decorrência de transgressões políticas, também a vida individual teve confiscada certa vez, na queda de Adão, a sua imortalidade garantida, e agora, por meio de Cristo, adquiria uma vida nova, potencialmente eterna, que, no entanto, podia novamente ser perdida em uma segunda morte, mediante o pecado individual (ARENDT, 2016a, p. 390-1).

Esse processo de sacralização da vida nivelou a vida activa apenas à necessidade da vida presente, como uma espécie de "posse" do mundo perecível em vista de uma eternidade. Outro espaço comum de sacralização era o direito romano, que aplicava a categoria de homo sacer àquele homem cuja vida foi excluída do direito "incluindo-a numa zona de anomia em que, paradoxalmente, fica capturada” (RUIZ, 2020, p. 91). Segundo Ruiz (2020, p. 89), Agamben resgata essa figura do direito romano para desenvolver "a tese da captura e exclusão biopolítica originária da vida pelo direito através da sacralidade", onde a pessoa tornada homo sacer "não era condenada legalmente à morte nem ao sacrifício, mas abandonada de qualquer direito e, como consequência, exposta a toda violência (AGAMBEN, 2002, p. 90 apud RUIZ, 2020, p. 91).

A vida humana é capturada pelo direito através da sacralização, em vista de "proteger a vida humana como algo mais que uma mera vida biológica animal”, mas ao mesmo tempo como dispositivo capaz de "relegar a vida da pessoa à mera condição de vida natural", num "limiar de anomia em que a vida humana se torna mera vida nua, pura vida natural" (RUIZ, 2020, p. 100), a exceção. Agamben (2004, p. 13) aponta ainda que "diante do incessante avanço do que foi definido como uma 'guerra civil mundial', o estado de exceção tende cada vez mais a se apresentar como o paradigma de governo dominante na política contemporânea". Como a sacralidade separa algo ou alguém do uso comum, ao mesmo tempo em que o direito a opera abençoando o cidadão com a proteção de sua vida, ao homo sacer é relegada negatividade da maldição, colocando sua vida num limiar vazio e abandonando-a à violência. Este paradoxo perdurou até hoje, pois

O direito continua a ser seletivo na proteção da vida, protege as vidas sagradas e abandona aquelas que considera mera vida natural. A violência constitutiva do direito lhe possibilita ameaçar a vida dos cidadãos com a sua 


\begin{abstract}
suspensão na forma da exceção soberana. O decreto do homo sacer condena a vida humana à exceção porque uma vontade soberana pode suspender o direito quando essa vida se tornar perigosa. A vontade soberana está acima e fora do direito, por isso pode suspendê-lo, e se utiliza dessa suspensão como técnica de controle biopolítico. A violência do direito também captura a vida pela normatização das condutas. A vida submetida ao direito, para poder existir, tem que se sujeitar às normas ditadas, caso contrário ela entrará na esfera das vidas perigosas e estará exposta à exceção. A vida controlada pelo direito é uma vida normatizada, sufocada pela norma (RUIZ, 2020, p. 109. Grifo nosso).
\end{abstract}

A vida que não se sujeita à norma e é retirada de seus direitos se aproxima da categoria arendtiana de displaced people, que se revelou a partir da experiência dos campos de concentração. Não encontrando lugar em nenhum lugar do mundo, resta o campo como lugar "natural" para os supérfluos. Lafer (2018, p. 222) aponta que o homo faber constrói o espaço público e a comunidade política em razão da faculdade de agir; por isso, as constituições e o direito são sujeitos ao poder que se dá na união da pluralidade dos seres humanos.

Com o excessivo uso da mentira organizada e a exacerbação da burocracia espetacular, surge a desobediência civil como "expressão de um empenho político coletivo na resistência à opressão", que "não se constitui como rejeição da obrigação política, mas sim como sua reafirmação" (LAFER, 2018, p. 223). Ela se constrói ainda de um agir baseado na associação entre homens no espaço público que se dissente da estrutura vigente resgatando a faculdade de agir e julgar, gerando o poder ou tomando-o das ruas onde foi deixado pela autoridade.

Daí ascende a importância da transparência e da verdade factual no espaço público, uma vez que a mentira e os segredos o corrompem; o direito à informação se mostra como condição sine qua non para "o juízo e a ação numa autêntica comunidade política” (LAFER, 2018, p. 224). Arendt (2016a, p. 322) levantará duas saídas para resguardar e reafirmar as verdades factuais: primeiramente o lugar da universidade e das humanidades, "que têm a obrigação de descobrir, conservar sob guarda e interpretar a verdade dos fatos e os documentos humanos", além de resguardá-la fora da política. A verdade, no entanto, entra em jogo na política através da imprensa, que deverá ser "protegida do poder governamental e da pressão social com zelo ainda maior que o poder judiciário, pois a importância função política de fornecer informações é exercida, em termos estritos, exteriormente ao domínio político”.

No prefácio de $O$ que é Política (2020, pp. 7-13), Kurt Sontheimer discorre que mesmo com as experiências totalitárias e o desamparo causado pela mentira organizada, Arendt acredita que os homens continuam capazes do dom de fazer milagres, de impor um novo começo; se a política surge do espaço entre os homens, o espaço da liberdade e 
espontaneidade, então a liberdade deve ser a razão e sentido da política. É a garantia do espaço onde os homens aparecem no mundo, o qual "está muito acima da compreensão usual e mais burocrática da coisa política, que realça apenas a organização e a garantia da vida dos homens" (p. 9). Assim,

Não podemos simplesmente nos contentar hoje com o desaparecimento histórico do fascismo e do comunismo, senão que devemos continuar conscientes de que a restrição da liberdade, a repressão da espontaneidade humana e a corrupção do poder através da violência também são uma ameaça constante para a política dos pretensos sistemas liberais (ARENDT, 2020, p. 10).

Diante disso, é oportuno lembrar, nas palavras de Arendt, que a capacidade de agir decorre do fato de que "cada um de nós veio ao mundo como um recém-chegado ao nascer. Em outras palavras, podemos iniciar alguma coisa porque somos inícios e, portanto, iniciantes"; a natalidade seria, então "condição ontológica sine qua non de toda política" (ARENDT, 2018b, p. 44), donde parte a "liberdade para ser livre". Podemos dizer com Dickinson (2017, p. 20) que "a desativação dessa maquinaria [o estado de exceção permanente e a máquina burocrático-espetacular] - nossa capacidade de torná-la inoperosa será possível mediante uma suspensão messiânica da própria suspensão (ou estado de emergência) que sustenta o poder decisivo do soberano", e com Agamben (2011, p. 83 apud DICKINSON, 2017, p. 20) que "é da filosofia que pode provir - com a sóbria consciência da situação extrema que o ser vivo que tem a linguagem atingiu na história - a indicação de resistência e de inversão de rota”. Assim,

O diferencial entre a simples, maciça inscrição do saber social nos processos produtivos, que caracteriza a fase atual do capitalismo (a sociedade do espetáculo), e a intelectualidade como potência antagonista e forma-de-vida passa pela experiência dessa coesão e dessa inseparabilidade [intelecto e pensamento da multitudo, o povo]. O pensamento é forma-de-vida, vida insegregável de sua forma, e em qualquer lugar em que se mostre a intimidade dessa vida inseparável, na materialidade dos processos corpóreos e dos modos de vida habituais não menos do que na teoria, ali e somente ali há pensamento. E é esse pensamento, essa forma-de-vida que, abandonando a vida nua ao "homem" e ao "cidadão", que a vestem provisoriamente e a representam com seus "direitos", deve tornar-se o conceito-guia e o centro unitário da política que vem (AGAMBEN, 2015, p. 18).

A potência destituinte do Estado burocrático e do uso de fake News como dispositivo aclamatório e sacralizador consiste, portanto, na ação e no pensamento que, nas palavras de Heidegger (apud ARENDT, 2018a, p. 17), "não traz conhecimento como as ciências; [...] não produz sabedoria prática utilizável; $[. .$.$] não resolve os enigmas do universo; [...] não nos dota$ 
diretamente com o poder de agir" pode tornar inoperoso o maquinário burocrático por cumprir o adágio de Catão com o qual a autora termina A condição humana (2016b, p. 403): "nunca se está mais ativo que quando nada se faz, nunca se está menos só que quando se está só consigo mesmo".

\section{Considerações finais}

Nossa problemática mostrou que a propagação das fake news se assemelha aos meios propagandísticos dos movimentos totalitários para mobilizar as massas e gerar insurreição contra os "inimigos"; somada à burocratização das democracias liberais, percebemos como as fake News são fenômenos que destroem a possibilidade de uma deliberação racional e que arrancam da população o chão da realidade. São a culminação do obscurantismo que marca a ascensão dos nossos últimos governantes, que usam e abusam da “opinião pública” para sufocar o movimento popular.

Pudemos também ver a atualidade e possíveis ligações entre os pensamentos de Hannah Arendt e Giorgio Agamben e encontrar, a partir de suas considerações, possíveis saídas para esse movimento trágico da máquina burocrática: cabe à filosofia e às humanidades serem guardiãs da verdade factual, bem como à mídia transmiti-la. Isso pode levar grupos a "ocupar o vazio" do poder ao toma-lo das ruas, reivindicando a liberdade, que é nada mais que a razão de ser da política, do espaço onde os homens podem fazer o "milagre" de gerar algo novo, uma "dissolução dos dispositivos que alicerçam uma forma de vida atrelada ao medo [...], causa do estado de exceção (permanente), nascedouro do homo sacer contemporâneo", levando a "fazer um novo uso das coisas ou, se se preferir, em que se pode, tal como Walter Benjamin visualizou na criança, brincar no mundo" (BARSALINI, 2020, p. 212), ou novamente, talvez, poder reconciliar-se com o mundo e "habitar nele como morada" (JARDIM, 2011, p. 21).

\section{REFERÊNCIAS BIBLIOGRÁFICAS}

AGAMBEN, G. Estado de exceção. Trad. Iraci D. Poleti. 2. ed. São Paulo: Boitempo, 2004. AGAMBEN, G. Meios sem fim: notas sobre política. Trad. Davi Pessoa. São Paulo: Autêntica, 2015.

ALMEIDA, P. A. O paradigma da sacralidade humana: uma leitura sobre o homo sacer na obra de Giorgio Agamben. Campinas: PUC-Campinas, 2020. 98p. 
ARENDT, A. A condição humana. Trad. Roberto Raposo. 13. ed. Rio de Janeiro: Forense Universitária, 2016a.

ARENDT, A. Entre o passado e o futuro. Trad. Mauro W. Barbosa. São Paulo: Perspectiva, 2016 b.

ARENDT, A. Origens do totalitarismo: antissemitismo, imperialismo, totalitarismo. Trad. Roberto Raposo. São Paulo: Companhia das Letras, 2012.

ARENDT, A. O que é política?. Trad. Reinaldo Guarany. 14. ed. Rio de Janeiro: Bertrand Brasil, 2020.

ARENDT, A. Liberdade para ser livre. Trad. Pedro Duarte. Rio de Janeiro: Bazar do Tempo, $2018 b$.

ARENDT, A. Crises da república. Trad. José Volkmann. 3. ed. São Paulo: Perspectiva, 2017.

ARENDT, A. A vida do espírito: o pensar, o querer, o julgar. Trad. Cesar Augusto R. de Almeida et. al. 7. ed. Rio de Janeiro: Civilização Brasileira, 2018a.

BARSALINI, G. O hōs mè e o simples uso de fato como chaves para a desativação de dispositivos contemporâneos. In: BARROS, D. F; BARSALINI, G; KIRCHNER, R. (orgs.). Religião e política na obra de Giorgio Agamben. Campinas: Saber Criativo, 2020. p. 195214.

DEBORD, G. A sociedade do espetáculo. Trad. Francisco Alves e Afonso Monteiro. Cascais (Portugal): Edições Antipáticas, 2005.

DELLA COLETTA, R. Bolsonaro mentiu ao falar de livro de educação sexual no 'Jornal Nacional'. $\quad$ El Pais, 2018. Disponível em: https://brasil.elpais.com/brasil/2018/08/29/politica/1535564207_054097.html?rel=mas.

Acesso em 09 dez. 2020.

DICKINSON, C. Ser e Agir, o Reino e a Glória: a Oikonomia Trinitária e a bipolaridade da máquina governamental. Trad. Luís Marcos Sander. Cadernos de Teologia Pública, São Leopoldo, Universidade do Vale do Rio dos Sinos, Ano XIV, vol. 14, nº 122, 2017.

DINIZ, N. S. A banalidade do mal em Hannah Arendt. Belo Horizonte: UFMG, 1995. 160p.

FROMM, E. The revolution of hope: toward a humanized technology. New York: Harper Colophon, 1970.

JARDIM, E. Hannah Arendt: pensadora da crise e de um novo início. Rio de Janeiro: Civilização Brasileira, 2011.

LAFER, C. Hannah Arendt: pensamento, persuasão e poder. 3. ed. Rio de Janeiro/São Paulo: Paz e Terra, 2018.

LELLIS, L. Vídeo que mostra urna eletrônica 'preenchendo' voto em Haddad é falso. Veja, 2018. Disponível em: https://veja.abril.com.br/blog/me-engana-que-eu-posto/video-quemostra-urna-preenchendo-voto-em-haddad-e-falso/. Acesso em 22 jul. 2020.

MAIA, A. G. B.; REINALDO, F. J. O. Amor mundi: uma resposta radical a uma desesperança política radical. Problemata: Revista internacional de filosofia, vol. $10, \mathrm{n}^{\mathrm{o}} 3, \mathrm{p}$. 59-72, 2019. 
MARANHÃO FILHO, E. M. A. et. al. "Fake news acima de tudo, fake news acima de todos": Bolsonaro e o "kit gay", "ideologia de gênero" e fím da "família tradicional". Revista eletrônica Correlatio, vol. 17, $\mathrm{n}^{\mathrm{o}} 2,2018$.

PFISTER, M. Oikonomia trinitária na obra de Giorgio Agamben: entre o reino e a glória, Opus Dei e altíssima pobreza. Campinas: PUC-Campinas, 2019.

RAMOS, M. Fake news: mais de dois boatos de fraude nas urnas desmentidos por dia. Piauí, 2018. Disponível em: https://piaui.folha.uol.com.br/fake-news-mais-de-dois-boatos-defraude-nas-urnas-desmentidos-por-dia/. Acesso em 22 jul. 2020.

RECUERO, R; GRUZD, A. Cascatas de Fake News políticas: um estudo de caso no Twitter. Galaxia, João Pessoa, vol. 10, nº 41, p. 31-47, 2019.

RUIZ, C. M. M. B. A sacralidade da vida e a vida nua: um problema ético e político. In: BARROS, D. F; BARSALINI, G; KIRCHNER, R. (orgs.). Religião e política na obra de Giorgio Agamben. Campinas: Saber Criativo, 2020. p. 89-112.

RUIZ, C. M. M. B. Implicações políticas da teologia no pensamento de Giorgio Agamben. Revista do Instituto Humanitas Unisinos Online, São Leopoldo, ed. 505, 2017. Disponível em: http://www.ihuonline.unisinos.br/artigo/6871-implicacoes-politicas-da-teologia-nopensamento-de-giorgio-agamben. Acesso em 09 dez. 2020.

SILVA, H. Estado de sítio, estado de necessidade, estado de revolução: os dispositivos (jurídicos) e a governabilidade na América Latina. In: BARROS, D. F; BARSALINI, G; KIRCHNER, R. (orgs.). Religião e política na obra de Giorgio Agamben. Campinas: Saber Criativo, 2020. p. 63-88.

SOUKI, N. A banalidade do mal em Hannah Arendt. Belo Horizonte: UFMG, 1995.

UOL. De fraude nas urnas a confisco de poupança: veja as "fake news" do $1^{\circ}$ turno. UOL, 2018. Disponível em: https://noticias.uol.com.br/politica/eleicoes/2018/listas/fake-newseleicoes-2018-urna-eletronica-pt-haddad-bolsonaro-psl-presidente.htm. Acesso em 22 jul. 2020 .

VASSALLO, L. et. al. Ministro manda Facebook derrubar 33 'fake news' sobre Manuela do ar. Estadão, 2018. Disponível em https://politica.estadao.com.br/blogs/faustomacedo/ministro-manda-facebook-derrubar-33-fake-news-sobre-manuela-do-ar/. Acesso em 21 jul. 2020.

VEJA. TSE manda Facebook derrubar 33 fake news sobre Manuela D’Ávila. Revista Veja, 2018. Disponível em: https://veja.abril.com.br/politica/tse-manda-facebook-derrubar-33-fakenews-sobre-manuela-davila/. Acesso em 21 jul. 2020.

VELASCO, C. É \#FAKE imagem em que Manuela D'Ávila aparece com camiseta 'Jesus é travesti'. G1, 2018. Disponível em: https://g1.globo.com/fato-ou-fake/noticia/2018/10/02/efake-imagem-em-que-manuela-davila-aparece-com-camiseta-jesus-e-travesti.ghtml. Acesso em 21 jul. 2020.

Artigo recebido em: 21/09/20

Artigo aprovado em: 05/12/20 